\section{Kidney \\ Blood Pressure Research}

Kidney Blood Press Res 2013;37:579-587

DOI: $10.1159 / 000355738$

Published online: December 03, 2013

Accepted: October 30, 2013

(C) 2013 S. Karger AG, Basel

www.karger.com/kbr

1423-0143/13/0376-0579\$38.00/0 NonCommercial 3.0 Unported license (CC BY-NC) (www.karger.com/OA-license), applicable to the online version of the article only. Distribution permitted for non-commercial purposes only.

\title{
Anxiety in Children and Adolescents with Chronic Kidney Disease - Multicenter National Study Results
}

\author{
Katarzyna Kiliś-Pstrusińska ${ }^{a}$ Anna Medyńska ${ }^{a}$ Piotr Adamczak ${ }^{b}$ \\ Irena Bałasz-Chmielewskac Ryszard Grendad Agnieszka Kluska-Jóźwiak ${ }^{\mathrm{e}}$ \\ Beata Leszczyńska ${ }^{f} \quad$ Ilona Olszak-Szot ${ }^{9}$ Monika Miklaszewska ${ }^{\text {h }}$ \\ Maria Szczepańska ${ }^{b}$ Marcin Tkaczyki Anna Wasilewskaj \\ Katarzyna Zachwieja ${ }^{h} \quad$ Maria Zajączkowskak ${ }^{k}$ Helena Ziółkowska $^{f}$ \\ Ilona Zagożdżonc Danuta Zwolińska ${ }^{\mathrm{a}}$
}

aDepartment of Paediatric Nephrology, Wroclaw Medical University, and ${ }^{b}$ Clinic of Paediatrics, Nephrology and Endocrinology, Silesian Medical University, Zabrze, 'Department of Pediatric \& Adolescent Nephrology \& Hypertension, Medical University of Gdansk, dDepartment of Nephrology, Kidney Transplantation and Hypertension, The Children's Memorial Health Institute, e'Department of Pediatric Cardiology and Nephrology, Poznan University of Medical Sciences, 'Department of Pediatrics and Nephrology, Medical University of Warsaw, '9Department of Nephrology, Children Hospital, Toruń,

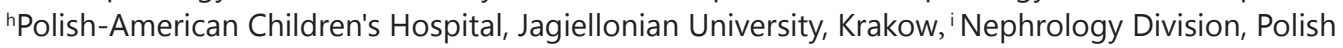
Mother's Memorial Hospital Research Institute, Łodź, jDepartment of Pediatrics and Nephrology, Medical University of Białystok, kDepartment of Pediatric Nephrology, Medical University of Lublin, Poland

\section{Key Words}

Anxiety • Chronic kidney diseases • Children • Adolescents

\begin{abstract}
Background/Aims: Chronic medical illness is a significant risk factor for the development of psychiatric disorders. The aims of the study were: to investigate the level of anxiety in children with chronic kidney disease (CKD) and to identify factors associated with the presence of that emotional problem. Methods: CKD children on hemodialysis $(H D, n=22)$, peritoneal dialysis $(P D, n=20$,$) and on conservative treatment (C T, n=95)$ were enrolled in the study. We used StateTrait Anxiety Inventory (STAI) for adolescents and STAI-C for children. Socio-demographic and physical factors were assessed. Results: There was a significantly higher level of anxiety-state among HD children (8-12 years) compared with other groups of participants of the same age and Polish population norms. The level of anxiety among adolescents (13-18 years), both anxiety-state and anxiety-trait, was significantly higher in the HD group compared with other
\end{abstract}




\section{Kidney \\ Blood Pressure Research}

groups, which did not differ among themselves. In the HD adolescents, there was a correlation between the anxiety-state and the duration of the disease as well as with the number of hospitalizations. PD adolescents in the mainstream education had higher levels of anxietystate and anxiety-trait compared with home schooled patients. Conclusions: Even though children and adolescents with CKD are at risk of developing a variety of emotional disorders, the level of anxiety among the researched group, with the exception of HD patients, was not significantly different than the level of anxiety among healthy subjects. Adolescents on HD who present a high level of anxiety should undergo long-term psychological treatment.

Copyright (C) 2013 S. Karger AG, Basel

\section{Introduction}

Chronic medical illness is a significant risk factor for the development of psychiatric disorders, including anxiety $[1,2]$. Psychiatric disorders may develop as a response to being ill or in the hospital, to a threatening environment, as a result of genetic and psychosocial factors or may be secondary to metabolic disturbances related to the specific medical illness, or as a combination of all these factors [3-6]. Psychiatric disorders can increase the severity of the preexisting physical illness by, among other ways, disturbing cardiac and nervous system, decreasing immune function or modulating nutritional conditions $[7,8]$. They can also influence patient compliance [9]. It is believed that moderate to severe anxiety affects symptom management, treatment adherence, medical outcome, and the ability of the child/ adolescent to cope with the illness [1, 2, 7]. Anxiety, a part of emotional status, is perceived as one of very important aspects of health-related quality of life [10-12]. This is why anxiety should be spotted early and appropriately treated.

Despite the increased significance of anxiety in somatic diseases, data on its appearance among children with chronic kidney disease (CKD) is limited and diversified. Bakr et al., in their research of 38 children with CKD, noted the appearance of anxiety in 1 among 19 patients treated with HD and in 1 patient with CKD in the pre-dialysis period [4]. However, in general, emotional disorders were noted among $52.6 \%$ of patients, in the majority of cases as adjustment disorders with depression (in 18.4\%) and depressive disorders (in 10.3\%). Amr et al. showed significantly higher results on the anxiety/depression scale of CBCL (the child behavior checklist) in the group of dialyzed and pre-dialyzed children than in the group of children without chronic diseases [13]. However, using another tool (SCICA, semi-structure clinical interview for children and adolescents) the authors noted, on the contrary, higher results in the reference group than in groups of sick patients. So far, no factors have been connected to the level of anxiety among CKD children. More information about anxiety among patients with CKD concerns mainly adults [14-18]. According to Livesley, depression and anxiety disorders are most commonly psychiatric comorbidity in adults with CKD [19]. In patients on dialysis, the prevalence rate for anxiety is about 30 to $45 \%$. Anxiety influences the quality of the patient's life and anxiety-trait was mainly related to emotional upset and social relationships $[17,20,21]$.

Advocating for the concept that the human being is the psychosomatic unity, we undertook in Poland multicentre studies of psychosocial aspects of children with CKD. There were two aims of the present study. The first was to investigate the level of anxiety in children with CKD, using State-Trait Anxiety Inventory (STAI) by Spielberger [22]. It is based on the theory that distinguishes between state anxiety, i.e. transitory emotional condition and trait anxiety defined as personality trait, a disposition to perceive evaluative situation as threatening [23]. The second one was to identify factors associated with the presence of those psychiatric problems. 


\title{
Kidney Blood Pressure Research
}

Kiliś-Pstrusińska et al.: Anxiety and Chronic Kidney Disease

\author{
Materials and Methods
}

\section{Participants}

Eleven out of twelve pediatric nephrology centers in Poland participated in the cross-sectional national study. The research was conducted on CKD children on hemodialysis (HD, n=22), peritoneal dialysis (PD, $n=20$,) and on conservative treatment (CT, $n=95)$.

All children on HD and PD have end stage renal disease (ESRD). ESRD patients were included to CKD group based on current CKD classification (CKD stage 5 contains ESRD) [21] and for the reason of more convenient analysis.

The inclusion criteria were as follows: (1) over 8 years of age, (2) stage III of CKD or higher according to KDOQI [24] based on the estimated glomerular filtration rate (eGFR) by the Schwartz formula [25], (3) CKD diagnosed at least 3 months prior to the begin of the study, and (4) informed consent. Exclusion criteria were: (1) history of severe to profound mental retardation, (2) renal, other solid-organ, bone marrow or stem cell transplantation, (3) cancer/leukaemia diagnosis, (4) hospitalization within 14 days (with the exception of a hospital stay for HD or PD), (5) initiation or change of dialysis modalities within the past 30 days, (6) a significant life event unrelated to their kidney disease in the past 30 days, such as losing a family member, severe illness of a family member, family structure changes, changing the living place. The study protocol adhered to the Declaration of Helsinki and was approved by the Ethics Committee of Wroclaw Medical University. A written informed consent of the children and their parents was obtained before enrollment in the study.

A semi-structured interview form developed by the investigators was used to determine the demographic characteristics of the participants, their schooling level, place of living and family structure. Medical files were analyzed to obtain the following data: primary diagnosis of kidney disease, patient's age at the time of CKD diagnosis, duration of illness, duration of renal care, family medical history and selected lab test results.

CT and PD patients were examined during their check-up appointments, but patients with HD were examined on the day of their hemodialysis session, just before arriving to the dialysis unit, before being connected to the machine. All dialysed patients were maintained on a single modality of dialysis. No patient switched.

\section{Methods}

The anxiety levels of the subjects were evaluated using a Spielberger STAI or State-Trait Anxiety Inventory for Children (STAI-C) (Mind Garden, Inc., Menlo Park, CA), depending on the age of the patient.

The STAI has been used extensively in anxiety-related research and clinical practice as a standard measurement tool for assessing anxiety in adolescents (13-18 year). It contains two 20-item questionnaires designed to measure how subjects feel "right now, at present circumstances" (state anxiety, form X-1) and how much anxiety represents a personality characteristic (trait anxiety, form X-2). Answers on the state anxiety scale range from 1 to 4 (1 [not at all], 2 [somewhat], 3 [moderately so], 4 [very much so]). Answers on the trait anxiety scale range from 1 to 4 (1 [almost never], 2 [sometimes], 3[often], 4 [almost always]). The total score ranges from 20 to 80. These scores represent low (20-30), average (31-49) and high ( $\geq 50$ ) levels of anxiety. The STAI has been translated and validated in Poland [26].

The STAI-C is a self-report questionnaire consisting of two 20 -item subscales that evaluate the state and the trait anxiety in children (8-12 years). The state subscale (form C-1) examines the shorter-term anxiety that is commonly specific to situations. The trait subscale (form C-2) measures longer-term anxiety which addresses how the child generally feels. Each item is scored from 1 to 3 . The higher scores indicate higher levels of anxiety. A validity and reliability study in the Polish pediatric population was performed by Sosnowski et al. [27].

The results of STAI-C and STAI in CKD patients were referred to the Polish population norms for children and adolescents, respectively [26, 27].

The children and adolescents answered the questionnaire (STAI-C and STAI, respectively) alone.

\section{Statistical analysis}

Statistical analyses were performed using $\mathrm{R}$ for Windows, version 2.15.1 (The R Foundation for Statistical Computing, Vienna, Austria) and MedCalc for Windows, version 12.3.1.0 (MedCalc Software, 


\section{Kidney Blood Pressure Research}

Mariakerke, Belgium). Quantitative variables were tested for normality distribution using the KolmogorovSmirnov test. Medians, quartiles, mean values and standard deviations were reported to describe the data, as appropriate. For comparison between groups the ANOVA test, the Kruskal-Wallis and Mann-Whitney U tests were used, as appropriate. Additionally, post-hoc analysis with Holm-correction was made. Spearman`s correlation analysis was used to determine the correlation between parameters. Accuracy of correlations was assessed using bootstraping method with 1000 samples. A p-value of less than 0.05 was considered statistically significant.

\section{Results}

The characteristics of the examined children are presented in Table 1. Some patients have additional diseases. In group I seven children have hypertension and one boy hemodynamically insignificant heart defect. In group II ten adolescents have hypertension, four - epilepsy, one allergy and four children have liver diseases.

Some HD children in group I had blood access via catheter (group $\mathrm{HD}_{1}$ ) and some via AV-fistula (group $\mathrm{HD}_{2}$ ). We performed analysis of STAI-C results in HD children depending on the kind of blood access (Table 2). The differences were not remarkable ( $\mathrm{p}=0.95$ for "state anxiety" and $\mathrm{p}=0.69$ for "trait anxiety"). In group II all children were hemodialysed using AV-fistula. So, this factor (blood access for HD) wasn't taken into account in further analysis.

There was a significantly higher level of the anxiety-state among children (8-12 years) treated with hemodialysis compared with other groups of sick children the same age and normative data (24). There were no differences concerning the level of anxiety-trait between the abovementioned groups (Table 2). Among adolescents, the level of anxiety-state was low among 26 patients (28\%), average among 58 patients (62\%) and high among 9 patients $(10 \%)$. The level of anxiety-trait was low among 18 patients from this group $(19.4 \%)$, average among 61 patients (65.6\%) and high among 14 patients (15\%). The level of anxiety among adolescents, both the anxiety-state and anxiety-trait, was significantly higher in HD group compared with other groups (on PD and CT) and with normative data (23), which did not differ among themselves (Table 3). The correlations between anxiety-state and anxietytrait were presented in Table 4.

In the whole group of sick children there were no significant correlations between the results of STAI-C scales (state, trait), STAI scales (state, trait) and such factors as: age of CKD diagnosis, the duration of the disease, the duration of renal care, the number of hospitalizations, serum creatinine, eGFR, and hemoglobin. There was no relationship between the level of anxiety (both state and trait) and the gender, the place of living, the family structure (full or incomplete, with or without siblings) or with the physical traits of patients, such as the body mass percentile and the height percentile. However, there were significant correlations in groups of children with CKD, singled out due to the modality of treatment. In the group of HD adolescents, there was a connection between anxiety-state and the duration of the disease $(r=0.58, p=0.04)$ and, below the statistical significance, between the anxiety-state and the number of hospitalizations ( $\mathrm{r}=0.46, \mathrm{p}=0.09)$. There was a higher level of anxiety (both trait and state) among PD adolescents with the mainstream education compared with home-schooled patients $(U=7.5, p=0.05$ and $U=8.5, p=0.07$, respectively). No significant correlation was noted in the group of children 8-12 years.

\section{Discussion}

Anxiety disorders are one of the most common emotional disorders in the general population [28]. It is believed that the prevalence of anxiety disorders among children/ adolescents with different chronic medical illnesses is higher compared to their healthy counterpart [1-3]. The rates of anxiety symptoms in pediatric patients range from 7 to $40 \%$, depending on the type of disease, examined group or used methods $[2,3]$. In the examined 


\section{Kidney \\ Blood Pressure Research}

Table 1. Socio-demographic and clinical characteristics of CKD patients

\begin{tabular}{|c|c|c|}
\hline Parameter & $\begin{array}{c}\text { Group I (8-12) } \\
n=44\end{array}$ & $\begin{array}{c}\text { Group II (13-18) } \\
n=93\end{array}$ \\
\hline Age, mean $\pm \mathrm{SD}$, years & $10.51 \pm 1.56$ & $15.57 \pm 1.44$ \\
\hline \multicolumn{3}{|l|}{ Gender } \\
\hline female & 13 & 43 \\
\hline male & 31 & 50 \\
\hline \multicolumn{3}{|l|}{ Cause of CKD } \\
\hline chronic glomerulonephritis & 7 & 16 \\
\hline malformations of kidney and urinary & 25 & 38 \\
\hline tract & 4 & 21 \\
\hline hereditary kidney disease & 4 & 15 \\
\hline others* & 4 & 3 \\
\hline unknown cause & & \\
\hline \multicolumn{3}{|l|}{ Family renal history } \\
\hline $\operatorname{yes}^{\wedge}$ & 4 & 17 \\
\hline no & 40 & 76 \\
\hline \multicolumn{3}{|l|}{ Place of residence (size) } \\
\hline village and town $<50,000$ inhabitants & 32 & 63 \\
\hline town $50,000-100,000$ inhabitants & 2 & 5 \\
\hline town $>100,000$ inhabitants & 10 & 25 \\
\hline Age of CKD diagnosis, median & 2.02 & 3.0 \\
\hline (quartiles; range), years & $(0.17,8.0 ; 0.01-11)$ & $(2.0,3.0 ; 0.01-16)$ \\
\hline CKD duration, median & 6.0 & 6.0 \\
\hline (quartiles; range), years & $(3.0,0.48 ; 0.6-12)$ & $(3.0,10.65 ; 0.25-17.75)$ \\
\hline Duration of renal care, median, & 5.0 & 5.21 \\
\hline (quartiles; range), years & $(2.7,9.5 ; 0.75-11.5)$ & $(2.71,9.86 ; 0.25-17.7)$ \\
\hline Number of hospitalization, median, & 3 & 3 \\
\hline (quartiles; range) & $(2,6 ; 0-12)$ & $(2,6 ; 0-12)$ \\
\hline \multicolumn{3}{|l|}{ CKD treatment modality } \\
\hline conservative treatment & 29 & 66 \\
\hline haemodialysis & 8 & 14 \\
\hline peritoneal dialysis & 7 & 13 \\
\hline \multicolumn{3}{|l|}{ Education } \\
\hline mainstream & 35 & 64 \\
\hline home-schooled & 9 & 29 \\
\hline \multicolumn{3}{|l|}{ Family } \\
\hline full & 41 & 73 \\
\hline single-parent family & 3 & 20 \\
\hline \multicolumn{3}{|l|}{ Sibling } \\
\hline yes & 39 & 82 \\
\hline no & 5 & 11 \\
\hline Serum creatinine, median & 2.21 & 2.24 \\
\hline (quartiles; range), $\mathrm{mg} / \mathrm{dl}$ & $(1.27,4.6 ; 1.0-13.05)$ & $(1.27,4.67 ; 1.1-13.8)$ \\
\hline eGFR, median & 24 & 24 \\
\hline (quartiles; range), $\mathrm{ml} / \mathrm{min} / 1.73 \mathrm{~m}^{2}$ & $(11.42,45.25 ; 5-59)$ & $(10.54,45 ; 5-58)$ \\
\hline Hemoglobin, mean \pm SD (range), g/dl & $11.78 \pm 1.67(9-14.5)$ & $11.81 \pm 1.67(8.5-15.0)$ \\
\hline \multicolumn{3}{|l|}{ Height } \\
\hline$\leq 3 \mathrm{pc}$ & 16 & 40 \\
\hline$>3 \mathrm{pc}$ and $\leq 10 \mathrm{pc}$ & 12 & 14 \\
\hline$>10 \mathrm{pc}$ and $\leq 50 \mathrm{pc}$ & 16 & 36 \\
\hline$>50 \mathrm{pc}$ & 0 & 3 \\
\hline \multicolumn{3}{|l|}{ Weight } \\
\hline$\leq 3 \mathrm{pc}$ & 14 & 37 \\
\hline$>3 \mathrm{pc}$ and $\leq 10 \mathrm{pc}$ & 9 & 11 \\
\hline$>10 \mathrm{pc}$ and $\leq 50 \mathrm{pc}$ & 21 & 29 \\
\hline$>50 \mathrm{pc}$ & 0 & 16 \\
\hline \multicolumn{3}{|c|}{$\begin{array}{l}\text { Group I -children aged 8-12, in whom STAI-C was used. Group II - children aged 13-18, in whom } \\
\text { STAI was used. CKD - chronic kidney disease. eGFR - estimated glomerular filtration rate. *The } \\
\text { other causes of CKD: neurogenic bladder, haemolytic uremic syndrome (HUS), acute renal failure } \\
\text { (other than HUS). }{ }^{\wedge} \text { Hereditary kidney disease, chronic glomerulonephritis, nephrolithiasis, } \\
\text { diabetic nephropathy, hypertensive nephropathy. Pc-percentile }\end{array}$} \\
\hline
\end{tabular}




\section{Kidney \\ Blood Pressure Research}

Kidney Blood Press Res 2013;37:579-587

\begin{tabular}{l|l}
\hline DOI: 10.1159/000355738 & (c) 2013 S. Karger AG, Basel
\end{tabular}

Published onlıne: December 03, 2013

www.karger.com/kbr
Table 2. State-Trait Anxiety Inventory for Children (STAI-C) comparisons of CKD and normative data

\begin{tabular}{lcc}
\hline & State anxiety & Trait anxiety \\
\hline PD, $\mathrm{n}=8$ & $28.75 \pm 6.11$ & $33.5 \pm 5.4$ \\
$\mathrm{HD}, \mathrm{n}=8$ & $37.71 \pm 13.76^{\mathrm{a}}$ & $33.14 \pm 12.55$ \\
$\quad \mathrm{HD}_{1}, \mathrm{n}=4$ & $39.00 \pm 15.25$ & $35.25 \pm 15.48$ \\
$\quad \mathrm{HD}_{2}, \mathrm{n}=4$ & $38.33 \pm 18.04$ & $30.33 \pm 9.61$ \\
$\mathrm{CT}, \mathrm{n}=29$ & $29.67 \pm 11.02$ & $30.2 \pm 7.5$ \\
Normative data*, & $29.24 \pm 7.45$ & $30.85 \pm 7.28$ \\
$\mathrm{n}=1239$ & \\
\hline $\begin{array}{l}\text { HD- hemodialysis, PD-peritoneal dialysis, CT- } \\
\text { conservative treatment.*- see References (24). }\end{array}$ \\
$\begin{array}{l}\text { a HD> normative data, HD> PD, HD>CT (ANOVA test); } \\
\text { p<0.01 }\end{array}$
\end{tabular}

Table 4. The correlation coefficients between state anxiety and trait anxiety in group I (8-12 years of age, STAI-C) and group II (13-18 year of age, STAI)

\begin{tabular}{lcccc}
\hline & \multicolumn{2}{c}{ Group I } & \multicolumn{2}{c}{ Group II } \\
& \multicolumn{2}{c}{ STAI-C results } & \multicolumn{2}{c}{ STAI results } \\
\hline & $\mathrm{r}$ & $\mathrm{p}$ & $\mathrm{r}$ & $\mathrm{p}$ \\
HD & 0.75 & 0.06 & 0.63 & 0.02 \\
PD & 0.47 & 0.02 & 0.85 & $<0.001$ \\
$\mathrm{CT}$ & 0.47 & 0.01 & 0.71 & $<0.001$ \\
\hline
\end{tabular}

HD- hemodialysis, PD-peritoneal dialysis, CTconservative treatment.

$\mathrm{r}$-Spearman rank correlation coefficient; $\mathrm{p}-\mathrm{p}$ value
Table 3. State-Trait Anxiety Inventory (STAI) comparisons of CKD and normative data

\begin{tabular}{|c|c|c|}
\hline & State anxiety & Trait anxiety \\
\hline$P D n=13$ & $37.16 \pm 8.04$ & $36.54 \pm 6.16$ \\
\hline $\mathrm{HD}, \mathrm{n}=14$ & $42.86 \pm 8.02^{\mathrm{a}}$ & $47.21 \pm 8.25^{a}$ \\
\hline CT, $n=66$ & $36.02 \pm 8.83$ & $41.2 \pm 8.36$ \\
\hline $\begin{array}{l}\text { Normative data*, } \\
n=1010\end{array}$ & 37.86 & 8.03 \\
\hline \multicolumn{3}{|c|}{$\begin{array}{l}\text { HD- hemodialysis, PD-peritoneal dialysis, CT- } \\
\text { conservative treatment**- see References ( } 23 \text { ). } \\
\text { aHD }>\text { PD, HD }>\text { MT, HD > normative data (ANOVA } \\
\text { test); } p<0.05\end{array}$} \\
\hline
\end{tabular}

cohort, the level of anxiety among the majority of children did not significantly differ from the level of anxiety among healthy children. In the group of children 8-12 years, we observed only a higher level of anxiety-state among children on HD, but in the group of adolescents, also only the ones undergoing HD, both the anxiety-state and anxiety-trait. This indicates that adaptation to the illness among patients with CKD is partially successful. Other authors indicated a significantly higher level of anxiety among children with such diseases as asthma, diabetes or epilepsy, may lead to a medical crisis and also make a child more anxious about being away from their caregivers [29, 30]. Although some studies have failed to find a link between asthma and depression in children [31].

Studies on emotional disorders among children with CKD are inconsistent. Some authors, assessing the social-behavioral functioning in children (also anxiety disorders), stated that they were similar to that of demographically matched peers [12, 32]. However, Fukunishi et al. noted the separation anxiety among as much as $65 \%$ of patients treated for CAPD and HD [33]. The interpretation of our results should be carried out carefully, because the number of the examined cohort and its diversity, depending on the manner of treatment and many socio-demographic traits, which cannot be avoided in clinical research. The level of anxiety, appropriate to the age, among the majority of patients may result from the fact that the disease was diagnosed in early childhood, the long duration of the disease, and the fact that patients had been under long-standing specialist renal care. The figures of the mentioned parameters (in the group of children 8-12 years, parameter medians: 2, 6, 5 years respectively) indicate that for most of its life, the child had been sick, thereby familiarizing the child with the disease which, becomes a natural state for the child. According to Soliday et al., depression and anxiety among patients and their next-to-kin are the strongest at the beginning of the disease [32]. After about 1 year following the diagnosis, the life of the family and the patients stabilizes. One of the concepts explaining this condition is the so-called adaptation to the stressor (the stressing factor) [34]. Similarly, Watnick et al., studying dialyzed patients, claimed that the symptoms of anxiety are most common at the beginning of the treatment [5].

The increased level of anxiety-state among patients on HD may be explained by the specificity of this renal replacement therapy. The hemodialysis sessions in themselves are commonly associated with acute feelings of anxiety. According to the studies by Feroze et al., anxiety among hemodialyzed patients was triggered when patients arrived for HD 

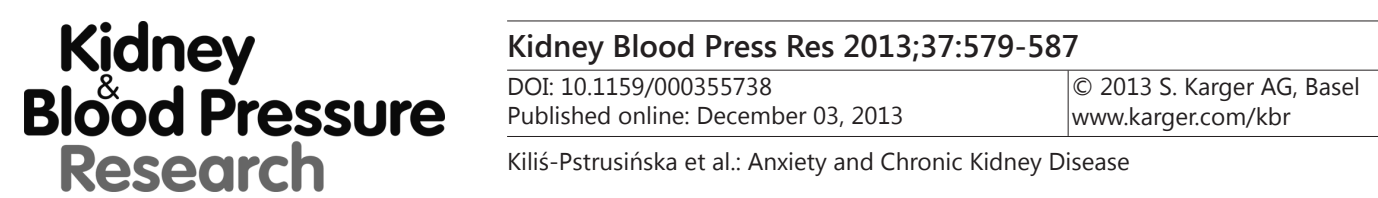

Published onlıne: December 03, 2013

www.karger.com/kbr

treatment, when they heard alarm and machine sound or when new staff connected the patient to dialysis machine [17]. These observations suggest that the modification in the conduct of hemodialysis may reduce some anxiety during the dialysis treatment.

The adolescents on HD are the group of patients, which requires the particular treatment due to the high level of anxiety. Their level of anxiety-state may be not only conditioned by the stress connected with HD treatment, but also with the high level of anxiety-trait. In our studies, we have shown the positive correlation between the state and the trait of anxiety, which is in accordance with the Spielberger results, as well as other authors [2, 22, 23]. Why does the anxiety as the personal trait becomes characteristic for hemodialysed adolescents? Adolescents 13-18 years of age may be aware of their limitations connected with the disease, which may result in their anxiety about the future $[2,28]$. Paradoxically, the extended duration of disease will not make it easier for the patients to adjust to the situation, but it will lead to the further enhancement of anxiety [29]. This suggestion may be supported by our observation of the positive correlation between the time of treatment and the level of anxiety-state. Anxiety may be exacerbated by the social isolation arising from the necessity of arriving to hemodialysis sessions and from frequent hospitalizations. To a smaller extent, the coincidence of such adverse factors concerns adolescent patients treated with PD, who are not "taken" from their natural family environment (treatment at home, the possibility to attend school, more time for contacts with peers). In our studies, we have not noted a higher level of anxiety in this group of patients. We observed, however, the connection between the level of anxiety with the type of education. Perhaps, children treated with PD and who have daily contact with healthy peers at school, discern their otherness in many ways, and therefore they underestimate their abilities.

In our studies, we have not shown the correlation between the level of anxiety with many demographical and clinical factors. Bakr et al. made similar observations concerning psychiatric disorders, among others, anxiety [4]. There was no correlation between the psychiatric disorders and age, sex, the duration of CKD, the duration and efficiency of HD and the severity of anemia among the group of children with CKD 5-16 years (average age 12 years).

The enhanced level of anxiety is certainly harmful and may pose a vicious circle comprised of mental disorders and unsatisfying compliance. Stating the level of anxiety and its treatment in the case of anxiety enhancement is not only significant in this age group, as has been stated in reference to adolescents undergoing hemodialysis. Children requiring the maintenance dialysis will never fully recover. Their emotional problems may be chronic. It was shown that anxiety and depression are the main psychiatric disorders among adults treated with HD $[14,16,18]$. Cukor et al., based on the long-term observations of adults with such abnormalities, stated that $34 \%$ of these patients had an intermittent course and as much as among $15 \%$ the persistent course [20]. It was also documented that anxiety and depression significantly lower the quality of life and may negatively affect the course of the disease [21]. In addition, suffering from anxiety or depression is a predictor for elevated mortality in adults $[15,16]$.

Our studies have some limitations. As mentioned above, the studied cohort was diversified. We have not taken into consideration a variety of factors that may determine the anxiety among sick children, such as e.g. the parental adjustment. Parents, their believes, emotions, attitude towards patients, have a strong influence on perceiving the life situation by patients [35]. We were aware that the family relationships can affect also emotional status of children. In current study this factor was not taken into account. However, we could evaluate the relationships in families of examined patients as proper on the basis of interview with children and their parents, medical history and our observations of patients. No data indicated "adverse family relationship".

Another factor connected with the level of anxiety, which we did not examine, may be the so-called sense of locus of control. This term describes the degree of perceived control that everyone has over its environment to get about favorable consequences. Hommel et al. noted the presence of increased depressive symptoms in a group of children with 


\section{Kidney \\ Blood Pressure Research}

juvenile rheumatic disease only when the child perceived little control over the situation [36]. Similarly, Birmele et al., assessing the health-related quality of life in adult chronic hemodialysis patients, stated that patients who viewed themselves as having control over their situation had better mental health [37]. The above observations not only suggest that the feeling of control may influence the level of anxiety in patients, but it can mean that patients should develop their inner locus.

It had been stated that anxiety is perceived as one of very important aspects of healthrelated quality of life (QoL). Thus the true influence of anxiety on QoL and the relationships between different dimensions of QoL and anxiety should be examined in the future studies.

\section{Conclusion}

To conclude, even though children and adolescents with CKD are at risk of developing a variety of emotional disorders, the level of anxiety among the researched group, with the exception of patients treated with hemodialysis, was not significantly different than the level of anxiety among healthy children. Adolescent patients who present the high level of anxiety should be subjected to long-term psychological treatment. More research is needed to examine the causes and potential methods for the prevention and treatment of that affective disorder.

\section{Conflict of Interests}

None declared.

\section{References}

1 Gandhi B, Cheek S, Campo JV: Anxiety in the pediatric medical setting. Child Adolesc Psychiatr Clin N Am 2012;21:643-653.

- Garralda ME Palanca MI: Psychiatric adjustment in children with chronic physical illness. Br J Hosp Med 1994;52:230-234.

3 Pao M, Bosk A: Anxiety in medically ill children/adolescents. Depress Anxiety 2011;28:40-49.

-4 Bakr A, Amr M, Sarhan A, Hammad A, Ragab M, El-Refaey A, El-Mougy A: Psychiatric disorders in children with chronic renal failure. Pediatr Nephrol 2007;22:128-131.

5 Watnick S, Kirwin P, Mahnensmith R, Concato J: The prevalence and treatment of depression among patients starting dialysis. Am J Kidney Dis 2003;41:105-110.

6 Jadoulle V, Hoyois P, Jadoul M: Anxiety and depression in chronic hemodialysis: some somatopsychic determinants. Clin Nephrol 2005;63:113-118.

7 Beesdo K, Knappe S, Pine DS: Anxiety and anxiety disorders in children and adolescents: developmental issues and implications for DSM-V. Psychiatr Clin North Am 2009;32:483-524.

-8 Hernandez EG, Loza R, Vargas H, Jara MF: Depressive symptomatology in children and adolescents with chronic renal insufficiency undergoing chronic dialysis. Int J Nephrol 2011;2011:798692.

-9 Lopes AA, Albert JM, Young EW, Satayathum S, Pisoni RL, Andreucci VE, Mapes DL, Mason NA, Fukuhara S, Wikström B, Saito A, Port FK: Screening for depression in hemodialysis patients: associations with diagnosis, treatment, and outcomes in the DOPPS. Kidney Int 2004;66:2047-2053.

10 Goldstein SL, Gerson AC, Furth S: Health-related quality of life for children with chronic kidney disease. Adv Chronic Kidney Dis 2007;14:364-369.

11 Grootenhuis MA, Stam H, Last BF, Groothoff JW: The impact of delayed development on the quality of life of adults with end-stage renal disease since childhood. Pediatr Nephrol 2006;21:538-544.

12 Fadrowski J, Cole SR, Hwang W, Fiorenza J, Weiss RA, Gerson A, Furth SL: Changes in physical and psychosocial functioning among adolescents with chronic kidney disease. Pediatr Nephrol 2006;21:394399. 


\section{Kidney \\ Blood Pressure Research}

Kiliś-Pstrusińska et al.: Anxiety and Chronic Kidney Disease

13 Amr M, Bakr A, El Gilany AH, Hammad A, El-Refaey A, El-Mougy A: Multi-method assessment of behavior adjustment in children with chronic kidney disease. Pediatr Nephrol 2009;24:341-347.

$\$ 14$ Kimmel PL, Patel SS: Quality of life in patients with chronic kidney disease: focus on end-stage renal disease treated with hemodialysis. Semin Nephrol 2006;26:68-79.

-15 Noohi S, Khaghani-Zadeh M, Javadipour M, Assari S, Najafi M, Ebrahiminia M, Pourfarziani V: Anxiety and depression are correlated with higher morbidity after kidney transplantation. Transplant Proc 2007;39:1074-1078.

16 Drayer RA, Piraino B, Reynolds CF 3rd, Houck PR, Mazumdar S, Bernardini J, Shear MK, Rollman BL: Characteristics of depression in hemodialysis patients: symptoms, quality of life and mortality risk. Gen Hosp Psychiatry 2006;28:306-312.

17 Feroze U, Martin D, Kalantar-Zadeh K, Kim JC, Reina-Patton A, Kopple JD: Anxiety and depression in maintenance dialysis patients: preliminary data of a cross-sectional study and brief literature review. J Ren Nutr 2012;22:207-210.

-18 Feroze U, Martin D, Reina-Patton A, Kalantar-Zadeh K, Kopple JD: Mental health, depression, and anxiety in patients on maintenance dialysis. Iran J Kidney Dis 2010;4:173-180.

19 Livesley WJ: Symptoms of anxiety and depression in patients undergoing chronic haemodialysis. J Psychosom Res 1982;26:581-584.

20 Cukor D, Coplan J, Brown C, Friedman S, Cromwell-Smith A, Peterson RA, Kimmel PL: Depression and anxiety in urban hemodialysis patients. Clin J Am Soc Nephrol 2007;2:484-490.

-21 Cukor D, Coplan J,Brown C, Peterson RA, Kimmel PL: Course of depression and anxiety diagnosis in patients treated with hemodialysis: a 16-month follow-up. Clin J Am Soc Nephrol 2008;3:1752-1758.

22 Spielberger CD: State-Trait Anxiety Inventory: A Comprehensive Bibliography. Palo Alto, CA, Consulting Psychologists Press, 1984.

23 Spielberger CD: Understanding Stress and Anxiety. London, Harper \& Row, 1979.

-24 K/DOQI Clinical Practice Guidelines for Chronic Kidney Disease: Evaluation, Classification and Stratification. Am J Kidney Dis 2002;39, suppl.1.

-25 Schwartz GJ, Munoz A, Schneider MF, Mak RH, Kaskel F,Warady BA, Furth SL: New equations to estimate GFR in children with CKD. J Am Soc Nephrol 2009;20:629-637.

26 Sosnowski T, Wrześniewski K: Polish adaptation of State-Trait Anxiety Inventory (STAI). Psychol Rev 1983;26:393-412.

27 Sosnowski T, Iwaniszuk D, Spielberger CD: Polish adaptation of State-Trait Anxiety Inventory for Children (STAIC). Psychol Studies 1987;27:67-79.

28 Richardson LP, Lozano P, Russo J, McCauley E, Bush T, Katon W: Asthma symptom burden: relationship to asthma severity and anxiety and depression symptoms. Pediatrics 2006;118:1042-1051.

29 Katon W, Lozano P, Russo J, McCauley E, Richardson L, Bush T: The prevalence of DSM-IV anxiety and depressive disorders in youth with asthma compared with controls. J Adolesc Health 2007;41:455-463.

-30 Goodwin RD, Bandiera FC, Steinberg D, Ortega AN, Feldman JM: Asthma and mental health among youth: etiology, current knowledge and future directions. Expert Rev Respir Med 2012;6:397-406.

-31 Ortega AN, Huertas SE, Canino G, Ramirez R, Rubio-Stipec M: Childhood asthma, chronic illness, and psychiatric disorders. J Nerv Ment Dis 2002;190:275-281.

-32 Soliday E, Kool E, Lande MB: Psychosocial adjustment in children with kidney disease. J Pediatr Psychol 2000;25:93-103.

33 Fukunishi I, Kudo H: Psychiatric problems of pediatric end-stage renal failure. Gen Hosp Psychiatry 1995;17:32-36.

34 Seyle H: Stress without distress. Philadelphia,J. B. Lippincott Co, 1974.

-35 Ye XQ, Chen WQ, Lin JX, Wang RP, Zhang ZH, Yang X, Yu XQ:Effect of social support on psychological-stressinduced anxiety and depressive symptoms in patients receiving peritoneal dialysis. J Psychosom Res 2008;65:157-164.

36 Hommel KA, Chaney JM, Wagner JL, Jarvis JN: Learned helplessness in children and adolescents with juvenile rheumatic disease. J Psychosom Res 2006;601:73-81.

-37 Birmelé B, Le Gall A, Sautenet B, Aguerre C, Camus V: Clinical, sociodemographic, and psychological correlates of health-related quality of life in chronic hemodialysis patients. Psychosomatics 2012;53:30-37. 